\title{
Training Needs and Attitudes of Greek Educationalists on Good Autism Education Practice for Children on the Autism Spectrum
}

\author{
Katingo Giannoulis ${ }^{1,}$, , Marios Koukounaras Liagkis ${ }^{2}$, Katerina Laskaridou ${ }^{3}$, Karen Guldberg ${ }^{4}$ \\ ${ }^{1}$ Psychology Department, The American College of Greece, Deree College, Athens, Greece \\ ${ }^{2}$ School of Theology, Department of Theology, National and Kapodistrian University of Athens, Athens, Greece \\ ${ }^{3}$ Laskaridis Foundation, Piraeus, Greece \\ ${ }^{4}$ Department of Disability, Inclusion and Special Needs, University of Birmingham, Birmingham, UK
}

Email address:

K.Giannoulis@clinicalconsultants.com (K. Giannoulis)

\section{To cite this article:}

Katingo Giannoulis, Marios Koukounaras Liagkis, Katerina Laskaridou, Karen Guldberg. Training Needs and Attitudes of Greek Educationalists on Good Autism Education Practice for Children on the Autism Spectrum. International Journal of Elementary Education. Vol. 10, No. 1, 2021, pp. 1-15. doi: 10.11648/j.ijeedu.20211001.11

Received: Februaru 8, 2021; Accepted: Februaru 18, 2021; Published: March 4, 2021

\begin{abstract}
The current scoping study conducted in Greece aimed to explore the training needs and attitudes held by educationalists on inclusive education for pupils with autism. Whilst educational policies and practice advocate for inclusive education for children with autism, actual provision is segregated between mainstream, special schools and multi-disciplinary therapy centers. These centers operate under the Ministry of Health and Social Welfare and are certified by the Ministry of Education. They collaborate with schools to ensure the seamless inclusion of children with autism into school. Whilst Greek educationalists believe on principle that inclusion is essential in the quest to foster community presence and integration for children with autism, in practice there are barriers to inclusive education; primarily these include the current financial crisis and budget cuts in Education as well as an anxiety on the part of teachers on how best to practice inclusive education, whilst protecting and maintaining the safety of autistic children. This ambivalence stems from insufficient knowledge, skills and experience and has significant implications for children with special needs, their families and for society as a whole. The current study aimed to address this ambivalence by, as an initial step, ensuring that all teachers are granted appropriate training and professional support so that children with autism are given the opportunity to flourish within inclusive educational settings.
\end{abstract}

Keywords: Training Needs of Greek Teachers, Good Autism Education Practice, Attitudes of Greek Teachers, Inclusive Education

\section{Introduction}

\subsection{Background Information on Autism Education in Greece}

To this day, in Greece, disability is seen as a personal tragedy or misfortune, defined primarily by medical difficulties and social isolation [1]. This outlook on disability is highly pertinent, as it doubtlessly influences the way in which it is managed. The current paper will attempt to highlight and discuss the challenges and prospects Greece is facing relating to the inclusive movement for children with autism.

The historical perspective in Greece needs to be addressed to understand the phase of inclusion Greece is currently in. It was not until the end of the 1930s that the educational needs of children with intellectual disabilities (then labeled "mental retardation") were considered for the first time in Greece [2]. At the time, these children were seen as "abnormal and retarded", uneducable in school. For those considered "educable", special schools or "special classes" (as they were called at the time) within mainstream schools were eventually introduced.

The inclusion movement for children with special educational needs has progressed in 3 phases in Greece: the first phase of "hidden and invisible inclusion" (1906-1984), the second phase during which special classes were 
established (1984-1989) and the third phase of European influence (1989-2000) [3]. From 1906 until 1950, the needs and welfare of children with special needs were addressed via private services and institutionalization. The ethos at the time was one of protecting children with special needs and of segregating them from society at large. During this initial phase, the first special school for "abnormal and retarded children" was established in 1937 in Athens. The period between the 1950s and the 1970s saw the establishment of more institutions and special schools to address a variety of special needs (e.g. children who were blind, deaf, who had cerebral palsy etc.) The overall aim of this period was to provide general education with a therapeutic emphasis. "Disability" came to be viewed more scientifically and systematically and the institutionalized establishment of medico-pedagogical centers contributed to this. A greater social acceptance of people with special needs characterized the third phase of special education development (from the 1970s until the early 2000s). This latter phase was defined by the provision of equal educational opportunities for all youngsters, based on inclusive education policies that emerged in the Greek educational system [4]. The practice of inclusion became established according to Greek Law (Law: 1566/1985) [5], in conjunction with "special classes" within mainstream schools for pupils with special needs. Pupils with autism were recognised for the first time as an autonomous group of children with special educational needs.

Greece is currently going through a fourth phase, one which, despite being constitutionally and scientifically established and supported, is not accompanied by substantial and structural modifications in educational practice [6]. Whilst inclusive educational legislation and policies are currently in place in Greece, there is concern that they are not being fully implemented [4] and they face a number of practical problems [7]. These practical problems are, to a great extent, magnified by the financial crisis in Greece and the subsequent education budget cuts. The cuts have resulted in phenomena like schools being shut down or forced to merge (leading to an increase in class size), teachers' salaries being reduced or teachers being encouraged to take early retirement. To add to this, party politics priorities coupled with clientelism lead to pronounced feelings of uncertainty and insecurity, in terms of the 'fate' of laws and policies [8]. Furthermore, despite the inclusion philosophy being in place, a significant improvement in the social status of people with disabilities has not yet been achieved and fair access to mainstream schools does not guarantee equal participation in education [1]. Gena concurs that the mere coexistence of children with and without special needs in communal school areas does not constitute a determining factor of essential inclusion [9]

\subsection{Current Education Provision for Children with Autism in Greece}

In Greece, children with autism have four schooling options, primarily determined by factors such as their intellectual level of functioning, their autism severity and their place of residence. Assessment is provided by Centers for Diagnosis, Differential Diagnosis and Support of Special Educational Needs and by public medical services [10]; these are the main statutory body that makes recommendations as to appropriate schooling and develops Individualized Education Plans. They specify the individual educational needs of a child diagnosed with a disability, but their role is currently advisory; should parents disagree with the recommendations made, they would need to opt for a Tribunal. The schooling options are: (a) to attend mainstream school without support (b) to attend the mainstream class with "parallel support" (a teacher assigned specifically to an individual child with autism). The Centres for Diagnosis, Differential Diagnosis and Support decide on the necessity and the hours per week of "parallel support" based on their assessment. Children with autism are automatically reevaluated annually for the renewal of this provision; (c) to attend an "integration class" with a specialist teacher for up to 15 hours per week together with other pupils with a range of special educational needs (SEN) (e.g. for math, reading and writing) and then to return to the mainstream class. Integration classes (originally named "special classes") found in a few primary schools are available for those children with SEN who have Individualized Educational Plans and who must be taught alongside their peers with the support of trained teaching staff (Law: 2817/2000) [11]. Recent data from the Institute of Educational Policy (2010) indicate that there are inclusion classes in 1562 primary schools all over Greece.

A naturalistic study conducted in 44 mainstream Greek schools revealed differences between the mainstream and the inclusion classes, namely: the mainstream classroom is traditional, with all pupils facing the teacher, it is based on teacher-centered education and lacks any educational accommodations, while the inclusion class encompasses differentiated material and individualized teaching and encourages active learning [12]. It has been estimated that since the implementation of the law, $70 \%$ of students with SEN have been placed in more than 1,000 primary schools that have inclusion classes while the remaining $30 \%$ attends a special school $[13,4]$. Whilst inclusion classes aim to meet the individual educational needs of specific children, ZoniouSideri et al. argue that their very existence merely perpetuates discrimination and stigmatization [4]. (d) The fourth schooling option for children with autism is to attend a special school. There are only 6 special schools for autism in the whole of Greece.

In practice, regardless of the type of schooling a child experiences, parents typically resort to private therapy for their children, in addition to school. This is predominantly because any educational provision for a child with autism is usually not deemed adequate by parents and also because there is a very strong ethos of therapy in Greek culture. Therapy takes the form of speech therapy, occupational therapy, special education, behavior therapy and/ or psychotherapy, delivered in private therapy centers as an after-school service. A study by Stampoltzis et al. found that $78 \%$ of their sample of children with autism received 
services apart and beyond their school placement [14].

An alternative schooling option for children with autism is to attend outpatient, day centers. These belong to the Ministry of Health and are certified by the Ministry of Education; thus they have to abide by the curriculum and other regulations belonging to the aforementioned ministry. According to Law 2444 of 2009 (FEK 2444/14-12-2009), these centers collaborate with schools and provide individual preparation programs for integration into school, when deemed appropriate. The day centers work on the child's social, communication and independence skills; they also provide educational input (e.g. reading, writing, numeracy). Their main aim is to improve any developmental challenges (e.g. communication weaknesses) and to prepare the child for a smooth school transition. They are staffed by multidisciplinary teams of speech and occupational therapists, special education teachers, psychologists, social workers and are led by a director who may be a child psychiatrist.

\subsection{Greek Autism-Specific Educational Policies}

In 2004 the Education Ministry's Institute of Educational Policy developed the first Analytical Curriculum for pupils with autism. According to this Analytical Curriculum, pupils with autism are seen as having the right to access a "broad and balanced" analytical curriculum [15]. This comprehensive curriculum is not limited to the learning objectives of the school, but also includes the development of broader skills, namely social skills, communication, play and self-care. This document postulates the need to take into consideration the specific cognitive features of children with autism. Moreover, it specifies that autistic pupils need specialized teaching accommodations, as traditional teaching practices are based on verbal communication and social integration which can be challenging for them. This highly detailed curriculum acts as a guide for the primary school teacher and stresses the need to understand the specific features of pupils with autism by recommending the following adaptations: (a) a structured learning environment (b) a fixed daily program (c) one-to-one teaching and minimal group teaching (d) alternative teaching methods (such as visual teaching material, physical guidance and support) and (e) enriching educational activities based on the young person's preferences and interests. The learning environment of a pupil with autism should aim to minimize confusion and anxiety typically stemming from environmental triggers.

The document also highlights teaching methodologies appropriate for children on the autism spectrum (e.g. structured teaching within structured environments, individualized daily timetables, visual supports, visual clarity specifying the beginning and the end of activities etc.) Moreover, it stresses the need to teach social and communication skills (including empathy training, emotional literacy, conversation skills, generalization of skills), play and self-care skills and it specifies behavioral training methods that can be used appropriately with children in skills-teaching activities (e.g. task analysis, prompting, fading, shaping, incidental learning, reinforcing and rewarding etc.) Challenging behaviors are also addressed. Furthermore, the most effective ways of teaching pupils with autism the core subjects taught in primary school (e.g. Math, literacy, art, music, IT, PE) are described in detail. It postulates that the progress of a child with autism should not need to follow the established educational goals used with neurotypical children. The Program is enlightening and clear in its message that the heterogeneity and unique cognitive profile and behaviors found in children with autism necessitate the adaptations of the mainstream curriculum so that autistic pupils are enabled to access the curriculum. However, in practice, this curriculum is rarely used; most teachers, in fact, are unaware of its existence as it has never been piloted nor put into effect.

\subsection{Teacher Training in Greece}

There are nine Greek Universities offering degrees in Preschool and Primary Education, but only one University, the University of Thessaly, offers an undergraduate degree in Special Education. Five Greek Universities offer postgraduate courses on Special Education, which cover inclusive education and SEN, but autism is only included in the curriculum at the University of Thessaly. Only those who have an undergraduate degree in Special Education or who have obtained a teacher training degree with postgraduate studies in Special Education are recruited to work in special schools and in the inclusion classes of mainstream schools. This illustrates the paucity of information on best autism education practice for primary school teachers working in mainstream schools.

\subsection{Issues and Challenges for Teachers Involved in the Education of Children with Autism}

The child's school is the context for their social communication [16]. A youngster's educational environment represents a fundamental stepping stone in the preparation for socialization and in the adoption of social values. Despite the educational reforms, the clear guidelines and procedural protocols that are in place in Greece for children with special needs, inclusion has not been embraced as a pervasive practice nor as an attitude wholeheartedly. Inclusion faces a number of difficulties (e.g. insufficient numbers of inclusion classes in mainstream schools; a scarcity of general and special needs teachers to meet the increasing needs of children with diverse challenges [7]. In a study conducted in Greece with children attending nursery and primary school, Gena identified the challenge of teaching children with autism social and communication skills [9]. If school inclusion does not incorporate socialization opportunities and a genuine acceptance of children with special needs, then stigmatization and marginalization cannot be avoided. Communication and socialization opportunities constitute a major social capital that a child with autism can be granted from the mainstream experience. 
The educational developments and reforms in Greece have obliged teachers to improve their skills and knowledge so that they are better placed to meet the needs of a diversified population of children. A survey of 155 primary school mainstream teachers working in Northern Greece revealed an overall positive attitude towards inclusion [17]. However, the respondents varied in their belief that accommodating children with a variety of disabilities in the mainstream classroom could work. Teachers with SEN experience were unsurprisingly more positive about inclusion than those who lacked such experience. This as well as other studies have emphasized that continuing professional training for Greek teachers is a priority if they are to rid themselves of their conservative attitude towards disability and adopt a more positive attitude towards inclusion [18].

One plausible explanation for educators' resistance towards inclusion has to do with their insufficient knowledge to ensure successful inclusion [19, 20]. When 229 Greek special education and mainstream primary school teachers were asked about their knowledge of SEN (namely general learning disabilities, autism and attention deficit hyperactivity disorder), they reported a need for more specialized training in SEN in order to be in a position to address appropriately the actual needs of the pupils [7]. A further study, examining the views of a diversified Greek teacher population on the management of children with autism also highlighted the need for specialized training and working experience to improve their efficacy as teachers of autistic children [21]. Greek teachers attending in-service training concurred that guidance, further knowledge and skills training in autism, as well as understanding the emotional needs of autistic children, are all crucial in enhancing their confidence in accommodating the educational needs of pupils on the autism spectrum [22].

Essentially, since the full inclusion of children with autism has not as yet been comprehensively nor adequately adopted in Greece, an individual approach to inclusion at every stage of learning is recommended. A youngster with autism may need one-to-one teaching initially and later be ready for inclusion in a mainstream class. More high functioning children with autism may learn well in a mainstream educational setting, but may need additional support as regards social skills. Other children with autism may benefit from partial inclusion and greater participation in a special school. Yet others would do best being included only in recreational activities within the mainstream environment. The child's age and cognitive profile, any behavioral challenges and their social awareness are all salient criteria in the development of an inclusion program for a child with autism [23]. Anecdotal evidence as well as autobiographical accounts written by individuals with autism emphasize that educators need to understand autism and, more specifically, need to understand the individual characteristics, cognitive profile as well as the learning and emotional needs of every child with autism so that they are given meaningful opportunities to access the most promising educational and social experiences [24-26].

\section{Materials and Methods}

The current study was part of an overall inter-disciplinary, multi-professional and transnational project involving Greece, UK and Italy [27]. It specifically aimed to identify Greek teachers' (a) attitudes towards the inclusion of pupils with autism in mainstream education, (b) feelings about working with autistic children and (c) training needs. These research questions necessitated the use of three data collection techniques: questionnaires, expert surveys and focus groups. Due to the richness of the data derived from these three techniques, the current paper will focus on the findings from the main questionnaire and the focus groups only.

The questionnaire was based on one originally developed by Avramidis, Bayliss, and Burden investigating the influence of teaching experience and professional development on Greek teachers' attitudes towards inclusion [28] (see Appendix 1). Items were modified to be relevant to pupils with autism. The questionnaire used a 5-point Likert scale. Participants were asked two additional open-ended questions, namely "Please list up to 3 competencies you think are essential for staff to have or to develop when working with pupils with autism?" and "What types of staff training would be most helpful in developing your own knowledge and skills?" After a pilot questionnaire was administered, 274 questionnaires were distributed (by hand and on-line) to professionals working in 16 outpatient therapy centers, 8 special schools and 10 mainstream nursery and primary schools. The questionnaire was initially tested for its reliability using Cronbach's alpha coefficient; this was carried out for all the main sections of the questionnaire, except the sample demographics and the open questions. Cronbach's alpha value was 0.807 which suggests good internal consistency; moreover, this indicates that the questionnaire is well designed and its use can produce valid results.

The focus groups included professionals involved in leadership and training. Information from the focus groups was deemed to compliment the data from the questionnaires to establish a more holistic picture. Three focus groups were run: one (FG1) for a group of professionals working in outpatient therapy centers, one (FG2) for professionals working in special schools and the third one (FG3) comprised of professionals working in mainstream schools. Eight individuals attended FG1, five attended FG2 and ten attended FG3. All three focus groups followed the format of a semi-structured interview and were run by two researchers. The interview contained 21 questions on three topics: staff practice, training needs and inclusion. (See Appendix 2.)

Statistical analyses were performed using descriptive statistics and, in some cases, inferential statistics (such as ttest and ANOVA) to analyse the questionnaire data. Means, standard deviations and percentages were calculated in order to describe the variables of the sample.

\section{Results}

\subsection{Findings from the Questionnaire}

The 274 questionnaires were completed by professionals, 
comprising of head teachers, mainstream teachers, support/shadow teachers, teachers working in integration classes, special education teachers, speech therapists, occupational therapists, psychologists and child psychiatrists. In terms of working experience, most professionals had up to 5 years of experience (36\%), followed by those who had 6-10 years of experience $(30 \%)$. The percentages of professionals who were more experienced with 11-15, 16-20 and more than 21 years of work experience were $16 \%, 7 \%$ and $11 \%$ respectively. As regards their experience of working with autistic children, approximately half of the participants (54\%) had fewer than five years of working experience, followed by those who had up to 10 years of experience $(27 \%)$, a further $11 \%$ had been working with children with autism between 11 and 15 years, $4 \%$ had more than 16 years of experience and $4 \%$ had more than 20 years of experience. The majority of participants $(84 \%)$ were working with children with autism at the time.

The majority of questionnaire respondents $(80 \%)$ reported that they had received some autism training and $61 \%$ had received training in specific autism interventions. Only $36 \%$ of mainstream teachers had received some ASD training, compared with $88 \%$ of professionals working in outpatient therapy centers. The types of training received ranged from seminars or conferences on overall autism awareness to longer accredited courses. A few participants had undergone academic courses on autism. A fair number of participants had also attended specific training in a variety of autism interventions (e.g. TEACCH (59\%), PECS (50\%), ABA (36\%), Social Stories (38\%), Pivotal Response Treatment (7\%) and Floortime (16\%). 30\% of respondents had also attended training in other relevant interventions, notably Early Bird, Intensive Interaction and Sensory Integration. Interestingly, mainstream class teachers, head teachers and teachers working as parallel support to pupils with autism within a mainstream school had undergone the least training of all professionals.

\subsection{Participants' Attitudes on Inclusion}

All participants $(\mathrm{N}=274)$ who completed the questionnaires agreed that the presence of a child with autism in the classroom is neither detrimental $(\mathrm{m}=2.17$, s.d. $=1.13)$ nor does it set a bad example for his/her peers $(\mathrm{m}=1.69$, s.d.=0.96). However, the majority $82 \%(\mathrm{~m}=1.9$, s.d. $=0.86)$ believed that educational practices in the mainstream classroom are unsuitable for children with autism. More specifically, participants held ambivalent views as regards what the most appropriate educational placement for children with autism should be. On the one hand, they believed that the needs of most autistic children are not best covered in special schools $(m=2.57$, s.d. $=0.99)$, but on the other hand, they did not believe that the integration class within a mainstream school is suitable either $(\mathrm{m}=2.92$, s.d.=1.06).

One of the key findings amongst those professionals (77\%) who completed the questionnaire stated that class teachers did not feel that they should be responsible for the education of children with autism when placed in mainstream school $(\mathrm{m}=2.44$, s.d. $=1.02)$. This finding has also been reported in other studies whereby it has been found that the responsibility for implementing inclusion in Greece should fall on 'expert' professionals, such as special education teachers and related professionals [29]. Avramidis and Kalyva found that when confronted with questions that directly examine the implications of undertaking full responsibility to implement inclusion in their classroom, the surveyed teachers' reactions were negative [17]. The issue of responsibility has been highlighted as one of the main problems within the educational system and with educational policy in Greece. Whilst current legislation is inclusive, in essence, participants testified that the way the educational system is set up is restrictive and partial.

The degree to which one's level of training in autism awareness affects attitudes towards inclusion was of particular interest. An overriding finding from the questionnaire respondents is that the more autism-specific training professionals had undergone, the more confident and the less stress they felt in their practice $\{t(269)=5.82$, $\mathrm{p}<0.000\}$. Unsurprisingly, those who had not received any autism training felt inadequate as regards working effectively with autistic children. More specifically, they felt more stressed $(\mathrm{m}=3$, s.d. $=1.02)$ and less confident $(\mathrm{m}=3.33$, s.d.=0.84). Moreover, a significant difference in reporting greater feelings of confidence between the professionals who had received autism training and training in interventions and the professionals who had not received any such training was detected $\{\mathrm{t}(269)=-4.33, \mathrm{p}=0.00\}\{\mathrm{t}(213)=-4.72, \mathrm{p}=0.00\}$.

\subsection{Feelings Associated with Working with Children with Autism}

The majority of participants $(68 \%)$ did not report feeling stressed $(\mathrm{m}=2.39$, s.d. $=1.01)$ nor nervous $(\mathrm{m}=2.50$, s.d.=1.10) about working with children with autism; however, those working in mainstream school reported feeling significantly more stressed $\{\mathrm{F}(3,236)=14.912$, $\mathrm{p}<0.000\}$, compared with professionals working in other settings. Moreover, teaching children with autism and other learning difficulties (LD) rendered teachers overall less confident in their competence and skills $(\mathrm{m}=3.75$, s.d. $=0.79)$. As one would expect, those working in mainstream schools $(\mathrm{m}=3.43$, s.d. $=0.87)$ reported less confidence than those working in outpatient therapy centers $(\mathrm{m}=3.93$, s.d. $=0.63)$ and special schools $(\mathrm{m}=3.95$, s.d. $=0.80)$. Another key finding is the level of confidence as regards managing challenging behavior. The professionals working in outpatient therapy centers reported feeling significantly more confident (71\%) in behavior management $(\mathrm{m}=1.86$, s.d. $=0.79)$, compared with those $(28 \%)$ working in mainstream schools $(\mathrm{m}=3.15$, s.d.=1.15). A further finding is that, predictably, the professionals who had undergone any autism training $(\mathrm{m}=3.98$, s.d. $=0.65)$ and training in autism-specific interventions $(\mathrm{m}=3.98, \quad$ s.d. $=0.65)$ reported increased confidence in their competencies compared with those who had not received any such training $(\mathrm{m}=3.33$, s.d. $=0.84)$ or specific training in autism-specific interventions $(\mathrm{m}=3.42$, 
s.d.=0.90). Furthermore, professionals who had undergone autism training of some sort $(\mathrm{m}=2.14$, s.d. $=1.03)$ and training in autism-specific interventions $(\mathrm{m}=1.94$, s.d. $=0.88)$ reported greater perceived ability to work effectively, compared with those who had not received any such training $(\mathrm{m}=3.34$, s.d. $=0.96)$ or specific training in autism interventions $(\mathrm{m}=2.76$, s.d. $=1.12)$.

On the basis of a content analysis of the open-ended question pertaining to the competencies professionals deemed important when working with youngsters with autism, the following themes emerged:

1. Understanding the autism spectrum, via autism-specific knowledge and training.

2. Internal drive: (being motivated, committed and driven in one's work and having a caring attitude).

3. Flexibility, imagination and humor: (professionals alluded to the need for creativity, flexibility and humor as paramount when supporting young people with autism).

4. Communication and cooperation (with the children themselves, with parents and other professionals involved in the child's care as well as the need for teamwork).

5. Patience, acceptance and tolerance in relation to diversity: (the absence of a critical attitude and stance was stressed when supporting pupils with autism).

6. Work-related skills: (qualities mentioned were professionalism, being observant, hardworking, persistent, having good organizational skills and a systematic way of working).

As regards what type(s) of training professionals would ideally seek, the majority of those working in mainstream schools $(84 \%)$ sought basic training on understanding the autism spectrum. Furthermore, $64 \%$ of the questionnaire respondents reported that they would find practical training the most useful and, more specifically, tailored to the individualized needs of pupils with autism. Training in practical interventions for use within schools was seen as a particular need by professionals working in mainstream schools (36\%) and in outpatient therapy centres (39\%) and less so by professionals working in special schools $(20 \%)$.

\subsection{Findings from the Focus Groups}

The participants' responses to the 3 topics addressed (inclusion, staff practice and training needs) were studied based on the issues raised. Two researchers used content analysis to reach consensus on the identification of key themes. Five themes emerged on inclusion:

Theme 1. Definition of inclusion

Outpatient center professionals defined inclusion as a process that supports and enables a child's adjustment in an educational setting. They further stressed that social inclusion is an important aspect of the process. They referred to a system that includes the family, the school and the community, a system that depends on collaboration and mutual communication. Special school and mainstream school educationalists described inclusion as a process that safeguards equal education opportunities for all children regardless of ability.

Theme 2. Implementation of inclusion

Participants in all three groups agreed that Greek schools are orientated towards inclusion practices, however it was felt that the outcome is not satisfactory as the State is not rigorous in enforcing inclusion guidelines. Some participants commented that inclusion is regarded as the physical presence of children in mainstream schools, rather than an ongoing process that supports children's needs.

Theme 3. Circumstances supporting inclusion

Participants from all three groups considered as an important condition of inclusion the good communication and the collaboration of the school with the family and the professionals that support the child. Furthermore, they concurred that the teacher's level of autism understanding and expertise is crucial in the effective inclusion of a child with autism and they also addressed the need for support and training of professionals working in mainstream and special schools. Outpatient therapy center professionals addressed the need to adapt the curriculum and to create autism-friendly educational material. Special school professionals referred to the need to discuss with children on the autism spectrum the issue of inclusion and their experience of school adjustment. Mainstream school professionals stressed that smaller class sizes could facilitate the better adjustment of a child with autism. It is interesting that only the professionals from special schools spontaneously considered the need to take into account the view of the child with autism in the development of an effective inclusion strategy.

Theme 4. Benefits of inclusion

Professionals working in both special and mainstream schools agreed that social inclusion should be part of inclusive education, a process that naturally starts at school and continues into adulthood. They saw inclusion as a step towards independence, where typically-developing children act as "role models". Furthermore, they perceived inclusion as an opportunity for all children to be happy within their school environment. Outpatient therapy center professionals pointed out that typically-developing children can benefit from inclusion in two ways: firstly, they can develop empathy and learn to accept diversity. Secondly, they can benefit from visually structured lessons and other techniques used to teach pupils with autism, as such tools are helpful for all children. Both special school and mainstream school professionals also reported that inclusion will be useful for children with typical development as they will have the opportunity to respect diversity, develop empathy and feel comfortable amongst youngsters with behavioral/social difficulties.

Theme 5. Obstacles to inclusion

Participants from all three groups agreed that inclusion is not yet satisfactorily implemented in Greece as it is applied in a disorganized and inconsistent manner. The practice of inclusion depends on individual good will and commitment rather than it being embraced and supported by the law and statutory guidelines. Moreover, professionals working in 
outpatient therapy centers stressed that even where inclusion is implemented, the social inclusion of pupils with autism when integrating them in mainstream schools was inadequate. They stressed that social participation is paramount in the implementation of inclusion. Participants from all three focus groups emphasized that successful cooperation between the school and the family was deemed as being one of the most crucial factors in determining the outcome of inclusion. Despite this claim, systematic and meaningful co-operation with families is seldom practiced.

A further obstacle identified by professionals from all three focus groups was the degree of functioning and challenging behavior of the individual autistic pupil; participant responses were divergent in that some believed children with significant challenging behavior should be educated in special schools, whilst others believed that all children should be in mainstream schools, regardless of ability level and degree of behavioral difficulties. Furthermore, even though they highlighted the need for the child's peers to be aware, to understand and to accept his/her differing needs, participants from all three groups did not feel equipped to take this task on.

Other barriers to inclusion mentioned included the following: once the child's educational assessment is complete, the provision of parallel support is typically delayed; many primary schools do not actually have specialized staff to uphold inclusion; support services may be inappropriate to the needs of the autistic child (e.g. two parttime parallel support teachers may be allocated to a child).

It is important to highlight the words of one academic, namely: "Inclusion is all about change. Changing not only what we teach, (the curriculum), but how we teach it (educational practices). It is also about transformation; transforming the structural obstacles against change, including the social basis of the way society defines the dominant terms for success vs. failure and ability vs. disability".

As regards training needs, $87 \%$ of professionals in the three focus groups stressed the need for autism-specific, continuing professional training. They identified the importance of gaining theoretical knowledge about autism first, followed by training in more practical teaching practices and social inclusion strategies. It is interesting that professionals working in special schools and outpatient therapy centers also mentioned that any training on an inclusive educational working model should also encompass: inter-disciplinary communication and cooperation, supervision and learning about how inclusion is adopted in other countries.

Responses on staff practice highlighted a number of interesting and salient issues. In response to the question relating to which areas they considered important for pupils with autism, participants from all three focus groups identified the improvement of socio-emotional understanding and social interaction as well as communication skills. Professionals working in outpatient therapy centers and special schools emphasized that education should also include the promotion of play skills, daily life and selfsufficiency skills (including sexuality and safety awareness). Stress management and self-understanding were also mentioned.

\section{Discussion}

Education and, more specifically, appropriate educational provision, is considered of germane significance for children with autism [30, 31]. Merely paying lip-service to a rightsdriven, inclusion movement without careful consideration and adequate funds to make inclusion successful may in fact be detrimental for a child with autism, as the problems produced by simple and unmanaged placement in mainstream school may well outweigh the benefits [32]. A range of educational provision should be on offer for children with autism in order to cater appropriately for their widely diverse needs [33]. Jordan argues that while no single approach can meet all the needs of those with autism, neither are needs entirely determined by individual behavior [34]. It is imperative for teachers to understand autism so that the child's learning needs are correctly identified and met. Developing a fundamental shared understanding of good autism practice and a common ideology of inclusion are vital, if society aims to create an environment where all children have the potential to thrive. Furthermore, those working in educational settings need to understand the typical difficulties experienced by those with autism so that their learning and well-being are enhanced. Teachers need to strive for empathic understanding and a willingness to work flexibly while steering away from rigidity and an expectation that the child must change and fit in.

The current study aimed to explore teachers' attitudes and feelings about including children with autism in mainstream educational environments and to identify their training needs. Whilst an ideology of inclusive education is embedded in the current Greek culture, interestingly, the views of Greek educationalists have been found to be ambivalent: on the one hand, inclusion is considered essential in the quest to minimize the stigmatization and the marginalization of children with autism; on the other hand, many propose that youngsters with autism should be educated within special schools so that they can be granted a safe and protective haven [29]. The current study clearly indicated that this kind of ambivalence primarily stems from a lack of autismspecific knowledge and skills and the associated anxiety that stems from these limitations; no doubt they could be resolved by ensuring adequate training and continual professional development, as well as support and supervision for teachers whose role is so crucial in the all-encompassing development and well-being of children with autism. Studies continue to outline that mainstream teachers have less knowledge than special school teachers about autism [35] and that teaching staff with little training in autism experience stress and 'occupational burnout' when placed in inclusive mainstream settings [36]. The reality is that Greek teachers in mainstream school are faced with having to manage the challenges of 
inclusion without adequate training, expertise and support. This unsurprisingly renders them concerned and hesitant to embrace inclusion in practice. Suitable training in autismspecific educational strategies for use within mainstream school settings will improve teachers' confidence and sense of self-efficacy and, will, at the same time, benefit both the pupils with autism and their typically developing peers [37]. Moreover, staff training regarding autism can lead to more informed expectations about child prospects [28].

Over the years, Greece has resorted to develop segregated services for youngsters with autism, with a divide between schools and therapy centers offering individual therapeutic input to children and consultation to parents. The limited expertise of teachers in mainstream education and the scarcity of autism-specific funding therein inevitably directed parents of children with autism to seek interventions outside the school setting. The dual approach Greece has established, encompassing both inclusion in mainstream schools and therapy centers, made up of professionals with autism expertise, could in fact be an ideal model of service provision, as long as inclusion is truly embraced and therapy centers work collaboratively with schools to support youngsters with autism and their families. Many skills being taught in therapy centers (e.g. communication and social skills training, play skills, perspective-taking, as well as the application and generalization of skills) could be undertaken by teaching staff and other relevant personnel within the school setting, as long as they are given adequate training, support and supervision. Therapy aims to grant children with autism the necessary skills and confidence to withstand adversity, develop resilience and maximize well-being. The Greek model of therapy services working in conjunction with education, whilst being culture-specific, could be a widelyapplicable, comprehensive working model for children with autism and their families, as long as teachers and therapists adopt a mutually respectful and complementary approach.

Equal participation in education by youngsters with autism, an understanding and a respect of diversity, an adequate grasp of the nature of autism and of the individual autistic child and, most importantly, autism-specific teacher training and expertise were all cited as essential prerequisites to the success of inclusive education in the current study. The findings on the beneficial effects of training on professionals' attitudes and feelings about inclusion are in line with the literature $[17,38]$. Whilst it was noted that professionals who had training in autism interventions were the least stressed and most confident and were the most positive about inclusion, training in autism interventions is typically of short duration. Research has shown that training needs to last longer if change in practice is not to be short lived [39]. It is therefore important that any training in best autism education practice is more longterm and in depth and that it includes features of continuing professional development and ongoing support. In addition, peers being aware and respectful of diversity and school staff working in partnership with parents are also vital features of effective inclusion. Lastly, and in fact most importantly, inclusion as a meaningful practice can only be achieved successfully if the views and opinions of individuals with autism are also considered [27, 40, 16]. The participation of autistic people in the development of an understanding of what constitutes a genuine inclusive school culture may present challenges and complexities, but it seems essential since non-autistic individuals continue to be responsible for educational policies, legislation and practices.

\section{Conclusions}

The current financial crisis in Greece, in conjunction with a prevalent view of autism as a medical disability, creates certain obstacles towards change and towards a genuine and whole-hearted assimilation of inclusion as a way forward for the education of youngsters with autism. However, despite these obstacles, professionals in Greece seek and strive for a truly collaborative model of training and practice, one that could be sustainable despite funding restrictions. An encouraging and empathic school environment, that is genuinely inclusive in its outlook and welcomes youngsters with autism, is essential if they are to be given every opportunity to flourish academically, socially and emotionally. Moreover, there is a reciprocal need for inclusion as both children with autism and typically developing children would benefit from having opportunities to interact and learn from each other. Inclusive education can only work if the ways in which autistic children think, learn, communicate and exhibit their understanding are genuinely valued and supported [41]. By assimilating children with autism in mainstream schools respectfully and meaningfully, while accommodating their cognitive, social and learning differences to enable them to reach their potential, anachronistic ideas about disability and diversity can be challenged and altered so that youngsters with autism can become valued adult members of the society they live in.

\section{Limitations}

The sample size of educator and therapist focus groups needs to be increased. In addition, future research ought to encompass groups of parents, student teachers and individuals with autism.

\section{Acknowledgements}

We would like to thank all members of the Transform Autism Education team, the Greek team, namely Elena Giouroukou, Eleni Angelidi, Katerina Sofianopoulou, Zosefina Tzonaka, Kaiti Serreti and Sofia Kapnogianni, the entire transnational team, the expert reference group, the teachers and practitioners who contributed to the research. Particular thanks go to the individuals with autism, especially Katerina Bakopoulou and George Ballas, who have been engaged with and commented on our work. 


\section{Funding}

This publication has been produced with the support of the Erasmus Plus Program of the European Union. This publication reflects the views only of the author/s, and the
Commission cannot be held responsible for any use that may be made of the information contained therein.

Disclosure statement: No potential conflict of interest was reported by the authors.

\section{Appendix}

\section{Appendix 1. Questionnaire}

\section{transform autism education}

Dear participant,

You are kindly invited to complete the following questionnaire, which is part of the Phase 1 data collection process of a three year research project entitled 'Transforming Educational Practice in Autism: enhancing the skills, knowledge and understanding of teachers in the UK, Italy and Greece'. This project is funded by the European Commission (Erasmus+: KA2Cooperation and Innovation for Good Practices) and it aims to promote equity and inclusion by enhancing the skills, knowledge and understanding of teachers and other practitioners who support children with autism aged between 5 and 10 years old.

We wish to find out about current attitudes and practices in autism education in the three countries and would be very grateful if you could take the time to complete this questionnaire. In order to be eligible to fill in this questionnaire you need to have worked with a child with autism at some point in your career.

The questionnaire is anonymous and you will not be asked to disclose your identity. You have the right to withdraw while completing the questionnaire. After having completed it, all questionnaires will be given codes and identification of your data and withdrawal will not be possible.

Section 1: About You

Please tick $(\sqrt{ })$ the answer/s which best describe/s your situation and write in the space provided if necessary.

1. What is your gender?

$\square$ Female

$\square$ Male

2. What is your current role?

$\square$ Headteacher

$\square$ Teacher

$\square$ Autism Advisory Teacher

$\square$ Teaching Assistant

Special Education Teacher

$\square$ SENCO

Support Teacher responsible for autism (assigned to work with a specific child/ren)

Other, please specify

3. What type of setting are you currently working in?

If you work in several settings, please choose ONLY ONE setting and respond to the rest of the questionnaire accordingly.

$\square$ Mainstream school

$\square$ Generic special school (Greece \& UK)

$\square$ Autism specialist school (Greece \& UK)

$\square$ Outpatient center (Greece only)

Other, please specify

4. What is the Year of the pupils you teach?

$\square$ Reception

$\square$ Year 1

$\square$ Year 2 


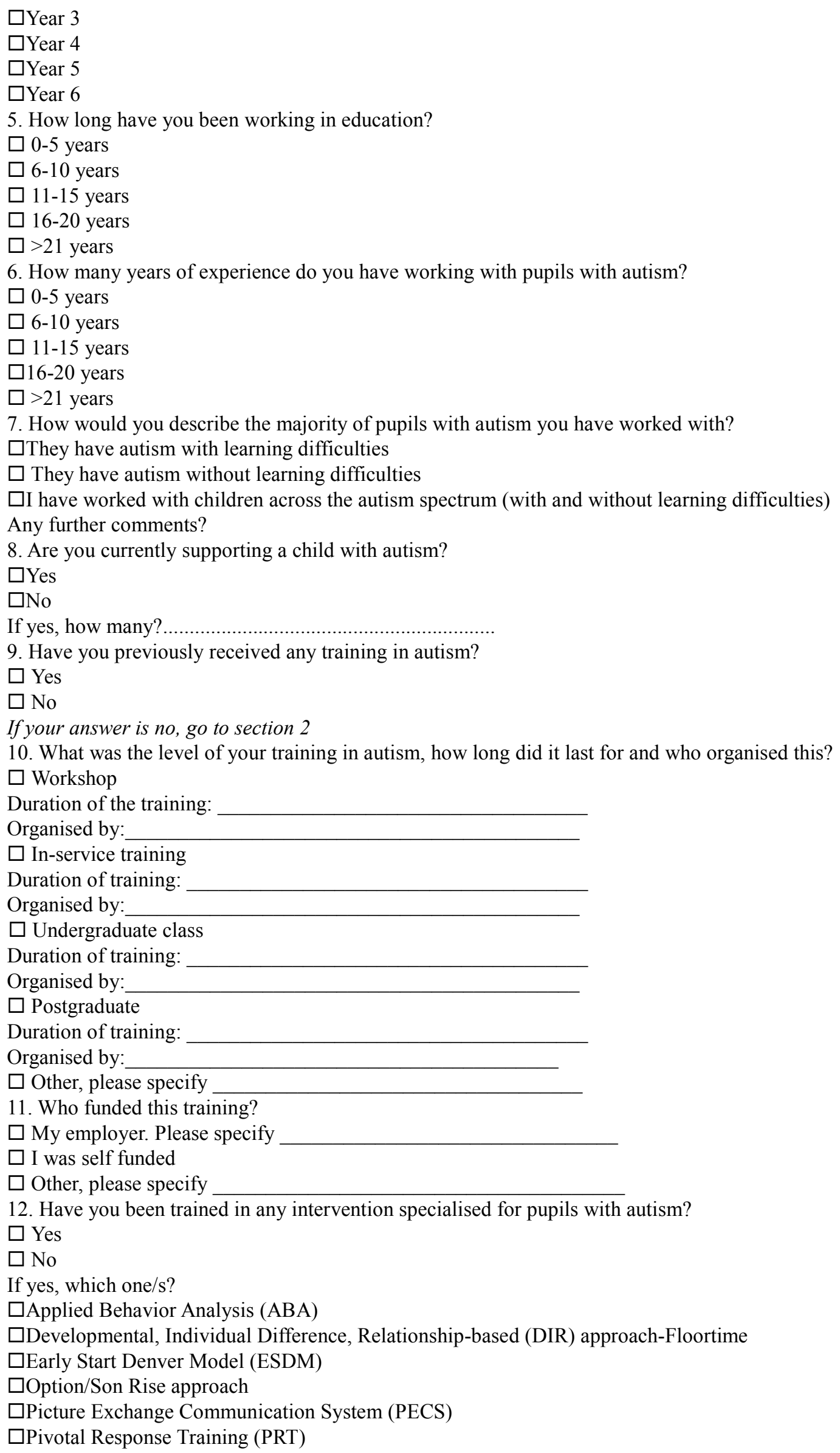


$\square$ Social Communication Emotional Regulation Transactional Support (SCERTS)

$\square$ Treatment and Education of Autistic and Related Communication Handicapped Children (TEACCH)

$\square$ Other/s, please specify.

13. Have you had any training by the Autism Education Trust? (UK only)

$\square$ Yes

$\square$ No

If yes, at what level?

$\square$ Level 1

$\square$ Level 2

$\square$ Level 3

14. Are there any comments you would like to add about yourself?

Section 2: Attitudes Towards the Inclusion of Pupils with Autism

Please rank the following statements according to how much you agree or disagree with them on a scale from 1 to 5 ( $1=$ strongly disagree, $2=$ disagree, $3=$ undecided, $4=$ agree and $5=$ strongly agree).

15. Teaching methods and strategies that are used with typically developing pupils can be appropriate for pupils with autism 12345

16. A pupil with autism can require extra attention and this can be detrimental to other pupils in the classroom

12345

17. The behaviour of pupils with autism might set a bad example to other pupils in the classroom

12345

18. Most pupils with autism can be well behaved in mainstream classrooms

12345

19. I can work with parents of children with autism as effectively as I work with parents of children without autism

12345

20. Including a child with autism in the mainstream classroom is likely to promote their social independence

12345

21. The needs of a pupil with autism can be best met in an autism resource base (UK only)

12345

22. The needs of a pupil with autism can be best met in a special school

12345

23. Pupils with autism should be given every opportunity to be educated in a mainstream classroom

12345

24. It is the mainstream teacher's responsibility to support pupils with autism when the latter are placed in their class

12345

25. Are there any comments you would like to add about attitudes towards the inclusion of pupils with autism?

Section 3: Feelings About Working with Pupils with Autism

Please rank the following statements according to how much you agree or disagree with them on a scale from 1 to 5 ( $1=$ strongly disagree, $2=$ disagree, $3=$ undecided, $4=$ agree and $5=$ strongly agree) .

26. I feel stressed when I work with pupils with autism

12345

27. I feel positive when I work with pupils with autism

12345

28. I feel confident when I work with pupils with autism

12345

29. I feel comfortable when I work with pupils with autism

12345

30. I feel worried when I work with pupils with autism

12345

31. Are there any comments you would like to add about attitudes towards the inclusion of pupils with autism?

Section 4: Your Practice

Please rank the following statements according to how much you agree or disagree with them on a scale from 1 to 5 ( $1=$ strongly disagree, $2=$ disagree, $3=$ undecided, $4=$ agree and $5=$ strongly agree).

32. I find it difficult to adapt my practice to accommodate the needs of pupils with autism 


\section{5}

33. I find it difficult to understand the behaviour of pupils with autism

\section{5}

34. I am confident about managing the behaviour of pupils with autism

12345

I am confident in working with the parents of pupils with autism

12345

I struggle with finding a range of opportunities to enable the pupil with autism to participate in the lesson

12345

I can understand when pupils with autism feel anxious and I can adapt my practice to minimise the pupil's anxiety

12345

I know how to help other pupils to accept the pupil with autism

12345

39. Based on the current support and the training that I have received, I do not feel able to support pupils with autism

12345

40. If I had the choice I would not choose to work with the pupil with autism

12345

41. Are there any comments you would like to add about your practice?

\section{Section 5: Your Opinion}

42. What types of staff training would be most helpful in developing your own knowledge and skills?

$\square$ Basic level training- general knowledge on autism

$\square$ Hands on training-adapted for a specific pupil(s) in my class

$\square$ Expert level training on how to train other professionals in my school

43. Please list up to 3 competencies (e.g. knowledge, skills or personal qualities) you think are essential for staff to have or to develop when working with pupils with autism.

a.

b.

c.

44. Please list up to three resources (e.g. books, equipment, assessment tools, adjustments) which you find particularly valuable in supporting pupils with autism. We would appreciate it if you could be as detailed as possible here so that we can locate the resources you propose. If it is a self-developed resource can you provide it to us as an attachment?

a.

b.

c.

45 . Are there any other comments you would like to add?

\section{Appendix 2. Focus Group Semi-Structured Interview}

Transform Autism Education Focus Group Interviews

\section{Dear Sir/Madame,}

You are kindly invited to participate in this focus group interview which is part of a 3 year research project entitled 'Transforming Educational Practice in Autism'. The project is funded by the European Commission and involves the UK, Greece and Italy. The project aims to promote equity and inclusion for children with autism aged between 5 and 10 in partner countries through enhancing the skills, knowledge and understanding of teachers and other school staff who work with them. This will be achieved through developing a set of quality indicators, a competency framework, a suite of training materials, a model of training delivery and a set of Open Educational Resources. The project will model itself on and complement the ground breaking Autism Education Trust (AET) partnership between Universities, local authorities, voluntary sector organisations, and schools in England.

Participation in this focus group interview is voluntary. Therefore, you have the right not to participate at all or not to answer questions you are not aware of or you do not feel comfortable with.

Please tick the box below as appropriate:

$\square$ I am happy to participate in this focus group interview

$\square$ I would prefer not to participate in focus group interview

Please print as appropriate:

Name: Date: 


\section{A. Staff practice}

1. Please list up to three resources (e.g. books, equipment, assessment tools, adjustments) which you find particularly valuable in supporting pupils with autism. Why do you think the specific resources are so valuable? We would appreciate it if you could be as detailed as possible here so that we can locate the resources you propose. If it is a self-developed resource can you provide it to us?

2. Please tell us 3 areas that you feel are especially important for pupils with autism (e.g. communication, independence skills etc). Why do you think so?

3. Which of these areas do you feel you need more training on (personally and as a setting) and why?

4. Please list up to 3 skills or personal qualities you consider as being essential for staff to have or acquire when working with pupils with autism. Elaborate on why each one of these is important.

5. Are there some of these skills or personal qualities in particular you would like to see included in the framework we plan to develop?

6. How might you use such a framework (e.g. to set personal development goals, to assess your/your staff performance)?

7. What would motivate you to use this framework?

8. What would discourage you from using it?

B. Training needs

9. What level/s of AET training has/have been most influential in developing your own knowledge and skills and why?

10. Which delivery mechanisms of training do you consider more beneficial (e.g. shadowing/ hands on training, adapted for a specific pupil(s) in my class/ lecture/ online/ face to face, theoretical/practical)?

11. Are there any barriers against your preferred type of training delivery?

12. Could you briefly describe an ideal training you have been to?

13. Do you think staff would like to be awarded a certificate when they complete their training?

14. If being awarded a certificate on successful completion was an option for you, how would you like to be assessed for this (e.g. portfolio, exams, shadowing) and why?

15. Could you think of any negative implications of such a certificate might entail?

16. Could you think of any negative implications training in such a model might entail?

C. Inclusion

17. What does inclusion mean to you?

18. Practically, how feasible is inclusion for children with autism?

19. What are the main benefits (for children with autism, for all children in the classroom)?

20. What are the main barriers?

21. What changes are required to accommodate the needs of children and young people with autism (e.g. in the educational system, in people's mentality/attitudes.

\section{References}

[1] Padeliadou, S. (2007). Social inclusion in school and transition into the work place for people on the autism spectrum: theoretical issues and educational interventions. Thessaloniki: Grafima [in Greek].

[2] Stasinos, D. (2001). Special education in Greece. Perceptions, institutions and practices: State and private initiative (19061989). Athens: Gutenberg [in Greek].

[3] Lampropoulou, V., and S. Padeliadou. (1995). Inclusive education: The Greek experience. In Inclusive education in Europe: Critical perspectives, edited by C. O'Hanlon, 49-60. London: David Fulton.

[4] Zoniou-Sideri, A., P. Karagianni, E. Deropoulou-Derou, and I. Spandagou. (2005). Inclusive classes in Greece: new games, old institutions. Paper presented at the Inclusive and Supportive Education Congress (ISEC), August 1-4, Glasgow. $\begin{array}{llll}\text { Accessed } & 26 & \text { April } & \end{array}$ http://www.isec2005.org.uk/isec/abstracts/papers_z/zoniouSideri_a.shtml

[5] Greek Official Governmental Gazette. Law 1566 30/9/1985 167 [in Greek]

[6] Padeliadou, S. (2005). School inclusion and ableism in education. In P. Agelides Inclusive Education: From the margins to inclusion. 107-122. Lefkosia: Kyproepeia [in Greek].

[7] Kalyva, E. (2010). Special Education: What do Greek Teachers Know about Learning Disabilities, Autism, and Attention-Deficit/Hyperactivity Disorder? In International Encyclopedia of Rehabilitation. edited by J. H. Stone, and M. Blouin, Accessed $26 \quad$ April 2020 http://cirrie.buffalo.edu/encyclopedia/en/article/263/

[8] Papadoulis, K. (2006). Clientelism, corruption and patronage in Greece: a public administration approach. Teaching Public Administration $26 \quad$ (1): $13-24$. doi: $10.1177 / 014473940602600102$.

[9] Gena, A. (2001). Inclusion programme of children with autism into preschool and $1^{\text {st }}$ grade on the basis of normative data. Psychology, 8 (1): 221-248 [in Greek].

[10] Syriopoulou-Delli, CK. (2010). A historical review of educational policy in Greece for children with pervasive developmental disorders, behavioral difficulties and other special educational needs. Review of European Studies, 2 (1): 2-14. doi: 10.5539/res.v2n1p2.

[11] Greek Official Governmental Gazette. Law 2817 14/3/2000 78 [in Greek]. 
[12] Padeliadou, S. (2001). The presence of individuals with special needs in the educational process: Exclusion or inclusion? Research into Greek education. K.E.E/Centre of Educational Research. Accessed 26 April 2020. http://www.kee.gr/html/researchfull.php?\&ID=5\&topicID=29 [in Greek].

[13] Stefa, A. (2001). Practices of inclusion and integration in mainstream schools: A critical approach. Topics in Special Education, 15 (1): 70-74.

[14] Stampoltzis, A., V. Papatrecha, S. Polychronopoulou, and D. Mavronas. 2012. Developmental, familial and educational characteristics of a sample of children with Autism Spectrum Disorders in Greece. Research in Autism Spectrum Disorders, 6 (4): 1297-1303. doi: 10.1016/j.rasd2012.05.004.

[15] Mavropoulou, S. (2003). Analytical Curriculum for pupils with autism. Athens: Ministry of National Education and Religious Affairs, Pedagogical Institute, Department of Special Education.

[16] Stephenson, J., and A. Adams. (2016). The social communication experience of children with autism in mainstream school. Good Autism Practice, 17 (2): 43-54.

[17] Avramidis, E., and E. Kalyva. (2007). The influence of teaching experience and professional development on Greek teachers' attitudes towards inclusion. European Journal of Special Needs Education, 22 (4): 367-389. doi: 10.1080/08856250701649989.

[18] Symeonidou, S. (2009). Trapped in our past: The price we have to pay for our cultural disability inheritance. International Journal of Inclusive Education, 13 (6): 565-579. doi: 10.1080/13603110801972069.

[19] Padeliadou, S., and V. Lampropoulou. (1997). Attitudes of special and regular teachers towards school integration. European Journal of Special Needs Education, 12 (3): 173183. doi: $10.1080 / 0885625970120301$.

[20] Padeliadou, S. (1995). The placement of children with special educational needs in mainstream classes: a research approach. Current Education: 3 month Inspection of Educational Issues, no. 82/83: 90-96 [in Greek].

[21] Syriopoulou-Delli, C. K., D. C. Cassimos, G. I. Tripsianis, and S. A. Polychronopoulou, (2012). Teachers' perceptions regarding the management of children with autism spectrum disorders. Journal of Autism and Developmental Disorders, 42 (5): 755-68. doi: 10.1007/s10803-011-1309-7.

[22] Mavropoulou, S., and S. Padeliadou. (2000). Greek teachers' perceptions of autism and implications for educational practice. Autism, 4 (2): 173-183. doi: $10.1177 / 1362361300004002005$.

[23] Harris, S. L, and J. S. Handleman. (1997). Helping children with autism enter the mainstream. In Handbook of Autism and Pervasive Developmental Disorders, $2^{\text {nd }}$ ed., edited by D. J. Cohen, and F. R. Cohen, 665-675. New York: Wiley.

[24] Hall, K. (2001). Asperger Syndrome, the universe and everything: Kenneth's Book. London: Jessica Kingsley Publishers.

[25] Lawson, W. (2000). Life behind glass. London: Jessica Kingsley Publishers.

[26] Williams, Donna. (2006). Nobody nowhere: The remarkable autobiography of an autistic girl. London: Jessica Kingsley Publishers.

[27] Guldberg, K., A. Achtypi, L. D’Alonzo, K. Laskaridou, D. Milton, P. Molteni, and R. Wood. (2019). Using the value creation framework to capture knowledge co-creation and pathways to impact in a transnational community of practice in autism education. International Journal of Research \& Method in Education, doi: 10.1080/1743727X.2019.1706466.

[28] Avramidis, E., P. Bayliss, and R. Burden. (2000). A survey into mainstream teachers' attitudes towards the inclusion of children with special educational needs in the ordinary school in one local education authority. Educational Psychology, 20 (2): 191-121. doi: 10.1080/713663717.

[29] Zoniou-Sideri, A., and A. Vlachou. (2006). Greek teachers' belief systems about disability and inclusive education. International Journal of Inclusive Education, 10 (4-5): 379394. doi: 10.1080/13603110500430690.

[30] Howlin, P. (2009). Children with Autism and Asperger Syndrome: A Guide for Practitioners and Carers. Chichester: Wiley.

[31] Konstantinidis, E. I., M. Hitoglou-Antoniadou, A. P. Luneski, D. Bamidis, and M. Nikolaiodu. (2009). Using affective avatars and rich multimedia content for education of children with autism. In Petra '09: Proceedings of the 2nd International Conference on Pervasive Technologies Related to Assistive Environments. Workshop on AHETA: Assistive Healthcare \& Educational Technologies for Special Target Groups. Corfu Greece. June 9-13, 2009, No. 58 (1-6). New York, NY: Association for Computing Machinery. doi: 10.1145/1579114.1579172.

[32] Reed, P. (2016). Interventions for autism: evidence for educational and clinical practice. Chichester: Wiley Blackwell.

[33] Parsons, S., K. Guldberg, A. Macleod, G. Jones, A. Prunty, and T. Balfe. (2011). International review of the evidence on best practice in educational provision for children on the autism spectrum. European Journal of Special Needs Education, $26 \quad$ (1): $47-63 . \quad$ doi: 10.1080/08856257.2011.543532.

[34] Jordan, R. (2005). Managing autism and Asperger's syndrome in current educational provision. Developmental Neurorehabilitation, 8 (2): $104-112 . \quad$ doi: $10.1080 / 13638490500054891$.

[35] Segall, M. J., and J. M. Campbell. (2012). Factors relating to education professionals' classroom practices for the inclusion of students with autism spectrum disorders. Research in Autism Spectrum Disorders, 6 (3): 1156-1167. doi: 10.1016/j.rasd.2012.02.007.

[36] Reddy, G. L. (2008). Special education teachers: Occupational stress, professional burnout and job satisfaction. New Delhi: Discovery Publishing House.

[37] Kofidou, C., C. Mantzikos, G. Chatzitheodorou, N. Kyparissos, and A. Karali. (2017). Perceptions and attitudes of educationalists on inclusive education of pupils with Autism Spectrum Disorder (ASD): a bibliographical review. Discourses! Theory and Practice in the Sciences of Treatment and Education, 3, 35-68. doi: http://dx.doi.org/10.12681/dial.11965 [in Greek]. 
[38] Tsakiridou, H., and K. Polyzopoulou. (2014). Greek Teachers' Attitudes toward the Inclusion of Students with Special Educational Needs. American Journal of Educational Research, 2 (4): 208-218. doi: 10.12691/education-2-4-6.

[39] Leyser, Y., and K. Tappendorf. (2001). Are attitudes and practices regarding mainstreaming changing? A case of teachers in two rural school districts. Education, 121 (4): 751761.
[40] Milton, D. (2014). So what exactly are autism interventions intervening with? Good Autism Practice, 15 (2): 6-14.

[41] Wood, R. (2019). Inclusive Education for autistic children: Helping children and young people to learn and flourish in the classroom. London: Jessica Kingsley Publishers. 